\title{
Retraining of interjoint arm coordination after stroke using robot- assisted time-independent functional training
}

\author{
Elizabeth B. Brokaw, MS; ${ }^{1-2}$ Theresa Murray, BS; ${ }^{1-2}$ Tobias Nef, PhD; ${ }^{3}$ Peter S. Lum, PhD ${ }^{1-2,4 *}$ \\ ${ }^{1}$ Center for Applied Biomechanics and Rehabilitation Research, National Rehabilitation Hospital, Washington, DC; \\ ${ }^{2}$ Department of Biomedical Engineering, The Catholic University of America, Washington, DC; ${ }^{3}$ Gerontechnology \\ and Rehabilitation Group, Artificial Organs Center for Biomedical Engineering Research, Universität Bern, Bern, \\ Switzerland; ${ }^{4}$ Washington DC Department of Veterans Affairs Medical Center, Washington, DC
}

\begin{abstract}
We have developed a haptic-based approach for retraining of interjoint coordination following stroke called time-independent functional training (TIFT) and implemented this mode in the ARMin III robotic exoskeleton. The ARMin III robot was developed by Drs. Robert Riener and Tobias Nef at the Swiss Federal Institute of Technology Zurich (Eidgenossische Technische Hochschule Zurich, or ETH Zurich), in Zurich, Switzerland. In the TIFT mode, the robot maintains arm movements within the proper kinematic trajectory via haptic walls at each joint. These arm movements focus training of interjoint coordination with highly intuitive real-time feedback of performance; arm movements advance within the trajectory only if their movement coordination is correct. In initial testing, 37 nondisabled subjects received a single session of learning of a complex pattern. Subjects were randomized to TIFT or visual demonstration or moved along with the robot as it moved though the pattern (time-dependent [TD] training). We examined visual demonstration to separate the effects of action observation on motor learning from the effects of the two haptic guidance methods. During these training trials, TIFT subjects reduced error and interaction forces between the robot and arm, while TD subject performance did not change. All groups showed significant learning of the trajectory during unassisted recall trials, but we observed no difference in learning between groups, possibly because this learning task is dominated by vision. Further testing in stroke populations is warranted.
\end{abstract}

Key words: arm, coordination, haptics, motor control, motor learning, robotics, stroke, synergies, therapy, upper limb.

\section{INTRODUCTION}

Approximately 795,000 individuals have a stroke each year in the United States [1], and stroke remains the most common cause of chronic disability for adults in the United States. The majority of survivors of stroke have limited use of their hemiplegic arm [2-3], with some studies reporting that after stroke a full 65 percent of individuals are unable to incorporate the hemiparetic upper limb into daily function [4-5]. Even mild impairment of upper-limb function after stroke significantly limits daily function and has been demonstrated to decrease health-related quality of life [6-8]. Reaching and grasping movements are components of many activities of daily living (ADLs) and are often impaired after stroke. Studies have reported a variety of impairments related to reaching and grasping, including decreased

\footnotetext{
Abbreviations: $3-\mathrm{D}=$ three-dimensional, $\mathrm{ADL}=$ activity of daily living, $\mathrm{ANOVA}=$ analysis of variance, $\mathrm{DOF}=$ degree of freedom, EMG = electromyography, $\mathrm{PD}=$ proportionalderivative, $\mathrm{ROM}=$ range of motion, $\mathrm{TD}=$ time-dependent, TIFT $=$ time-independent functional training.

*Address all correspondence to Peter S. Lum, PhD; Biomedical Engineering, The Catholic University of America, Pangborn Hall, Room 131, 620 Michigan Ave NE, Washington, DC 20064; 202-319-5657; fax: 202-319-4287.

Email: lum@cua.edu

DOI:10.1682/JRRD.2010.04.0064
} 
muscle activation and weakness [9-12], disrupted interjoint coordination [13-16], decreased smoothness of movement [17-18], and dyscoordination between reach and grasp movements [19].

Abnormal interjoint coordination is commonly observed after stroke and is the focus of this study. The most studied abnormal neural synergy is the inability to simultaneously abduct the shoulder and extend the elbow [20-23]. While compensatory strategies (excessive trunk movement) can overcome this impairment, recovery of interjoint coordination is possible with a focused intervention [24]. Importantly, therapy strategies that promote relearning of normal interjoint coordination and movement kinematics may critically affect actual real-world use of the limb in ADLs [25], while therapies that allow use of compensatory strategies may impede this process [26-27]. The concept that compensatory strategies can mask more normal movement patterns was demonstrated by Michaelsen et al. [28-29]. They showed that in a single session, when the trunk is restrained, reaching patterns in the shoulder and elbow improve toward normative performance [28]. Therefore, we have developed a therapy method that inhibits compensatory strategies and promotes learning of proper interjoint coordination during reaching movements.

The use of robotic devices to treat upper-limb movement deficits is increasingly accepted, with several commercial devices now available for the arm and hand [3031]. The earliest of these robots were end point-based, attached to the forearm and hand, and controlled movements in extrinsic coordinates. These important first studies with MIME (Mirror Image Movement Enabler) [3233], ARM Guide [34-35], and MIT-Manus [36-37] demonstrated that robot-assisted movement was safe and well tolerated by patients with stroke and resulted in measurable reductions in impairment. Meta-analyses and systemic reviews of clinical trials have shown that using upper-limb robots has some advantages in recovery of strength and movement ability when compared with active control groups that did not use robots, but no advantages were seen for using robots in recovery of ADL ability [38-40]. However, these reviews group together the effects of a wide range of robots and control strategies, and further studies may eventually reveal that a subset of these approaches or new, untested approaches are effective in restoring ADL ability. A recent multisite clinical trial of several upper-limb robots found them comparable to dose-matched conventional therapy, but superior to usual and customary care in motor function scales at 36 weeks [41]. In contrast, two recent clinical trials of lower-limb robots found them inferior to conventional methods [42-43]. This finding suggests that the type of robot and the control modes used do affect outcome, and further studies are needed to optimize robotic approaches to movement therapy.

One approach for robotic assistance is provision of an end point "tunnel" in three-dimensional (3-D) space that guides the hand toward the target but allows the subject to control movement timing [32,44-45]. However, in a study of the electromyography (EMG) patterns after training with an end point tunnel controller, a compensatory strategy using excessive shoulder girdle movement appeared to compromise learning of normal reaching patterns [46]. Use of proximal joints in compensatory strategies can be made ineffective with an appropriate control law and an exoskeleton that has direct control of arm joints. Also, exoskeletons allow implementation of guiding constraint walls in joint space instead of end-point space, affording targeted training of specific interjoint coordination patterns. Other advantages of a joint-based robot-human interaction strategy relate to motor learning studies in nondisabled subjects. Motor learning of novel force fields appears encoded in intrinsic or joint-based coordinates [47]. Furthermore, multijoint movements may be learned as joint coordination ratios or relative joint patterns [4849]. Motivated by these results, researchers have focused on developing exoskeleton robots that directly control limb degrees of freedom (DOFs) [50-56].

Similar to a recently reported training mode developed for gait training [57], we have developed a robotic intervention for arm rehabilitation that specifically targets impaired interjoint coordination by requiring active patient participation in coordinating multiple joints. We implemented this training mode in the ARMin III exoskeleton [50], which can apply torques directly to each of the six DOFs of the arm (three shoulder torques, elbow flexion/ extension, supination/pronation, wrist flexion/extension). The ARMin III robot was developed by Drs. Robert Riener and Tobias Nef at the Swiss Federal Institute of Technology Zurich (Eidgenossische Technische Hochschule Zurich, or ETH Zurich), in Zurich, Switzerland. The new control method, called time-independent functional training (TIFT), allows the patient to learn the desired movement in joint space at his or her own pace, while still requiring the patient to actively complete the movement. The TIFT mode was designed for retraining functional tasks after 
stroke, but any trajectory and any number of arm DOFs can be used to control the movements. This system provides guiding joint-space walls to keep the subject close to the ideal joint-space path and holds the subject's arm at the current point in the trajectory if he or she stops actively producing the required interjoint coordination. This approach is consistent with several principles of motor learning [58]. For example, the guiding walls assist with completion of the task with correct joint kinematics while minimally interfering with the map between muscle activation patterns and actual movement. We will show that this mode is passive in the sense that no positive work is done on the limb by the robot. This guarantees that the timing between correct muscle activation patterns and movement afference is preserved, which is important for cortical plasticity [59-60] and is often lost in assistance modes in which timing is prescribed by the robot and not the patient. Also, the production of a joint torque pattern that has a positive component in the desired jointspace direction is "rewarded" with advancement along the trajectory, while improper joint coordination patterns are "punished" by lack of movement. This operant conditioning approach is the basis of constraint-induced therapy [61]. Irrespective of the movement speed the subject chooses, if movement is within a deadband around the targeted joint coordination trajectory, movement proceeds with no intervention from the robot.

Comparing the relative effectiveness of different robotic therapy modes is difficult because of the literally infinite number of possible modes and the slow and tedious recovery process in subjects with stroke undergoing training. Short of performing clinical trials, one approach to assessing the potential of a new therapy mode is motivated by the hypothesis that recovery of movement after neurological injury is related to motor learning of novel environments and acquisition of skill in nondisabled subjects [58,62-63]. Common neural mechanisms may provide the foundation for these behavioral changes. This notion is attractive and has motivated the application of motor learning principles into the practice of physical and occupational therapy [64-67]. Based on this hypothesis, the effectiveness of robotic therapies can be initially tested by study of nondisabled subjects' learning when exposed to the new training mode compared with other training modes. Since nondisabled subjects can already perform all the commonly used movements targeted for functional training in patients with stroke, studies focus on learning a difficult or novel task when assisted by the robot. This approach has led to insights into the role of haptic guidance in motor learning, which may have implications for stroke recovery [68-70].

Although novel path learning is typically achieved through repetitive task practice, visual demonstration has also been shown effective for learning a new path [70]. The mirror neuron system has been identified as the likely neurophysiological basis for the motor system to learn from observing movements in another person [71]. In fact, motor imagery may produce cortical plasticity similar to what results from actual repetitive practice [72]. For these reasons, the potential confounding effects of action observation need to be isolated when visual information is available during the haptic guidance.

We describe in detail the implementation of the TIFT mode with the ARMin III robot and discuss the advantages of this approach compared with other similar modes. In initial testing, nondisabled subjects received a single session of training of a complex movement trajectory with one of three training modes. One subject group received TIFT, while another group received the commonly used robotic approach of asking subjects to "move along with the robot" as it moves the limb in a prescribed timedependent (TD) trajectory (TD training). The third subject group learned the trajectory by observing the robot move the arm of a stand-in person through the trajectory. We studied motor learning during the training task as well as learning rates during recall performance of the trajectory without robotic assistance. We hypothesized that when compared with the other training modes, the TIFT would induce faster and larger reductions in trajectory recall error because of the highly interactive nature of the TIFT, which promotes more active engagement during the training than the other two modes. The vision group was expected to have the smallest and slowest reductions of trajectory recall error because the TIFT and TD training groups have proprioception and visual information during training, while the vision group only has the visual demonstration information. We also expected that in the TIFT and TD groups, kinematic error and robot-applied guiding torque would decrease during the training trials.

\section{METHODS}

\section{Motor Learning Testing}

Thirty-seven nondisabled subjects were recruited and divided randomly into the three training groups: TIFT, 
visual demonstration, and TD training. All subjects underwent two TD movements through the desired path with the subject's arm passive in the robot; they then performed a recall of the path with no robotic assistance so we could measure the subject's initial performance of the task before training. Subjects performed 8 blocks of 10 repetitions of the task training with recall testing and $1 \mathrm{~min}$ of rest between each block. We gave no feedback to subjects about their performance quality during recall or training. We did not use the ARMin III visual display because meaningful performance feedback of adherence to a complex 3-D path is difficult to provide in a two-dimensional display, and graphical feedback could increase visual dependence in learning the path.

We chose the shoulder elevation and elbow flexion/ extension paths shown in Figure 1, largely because interjoint coordination is known to be impaired between these
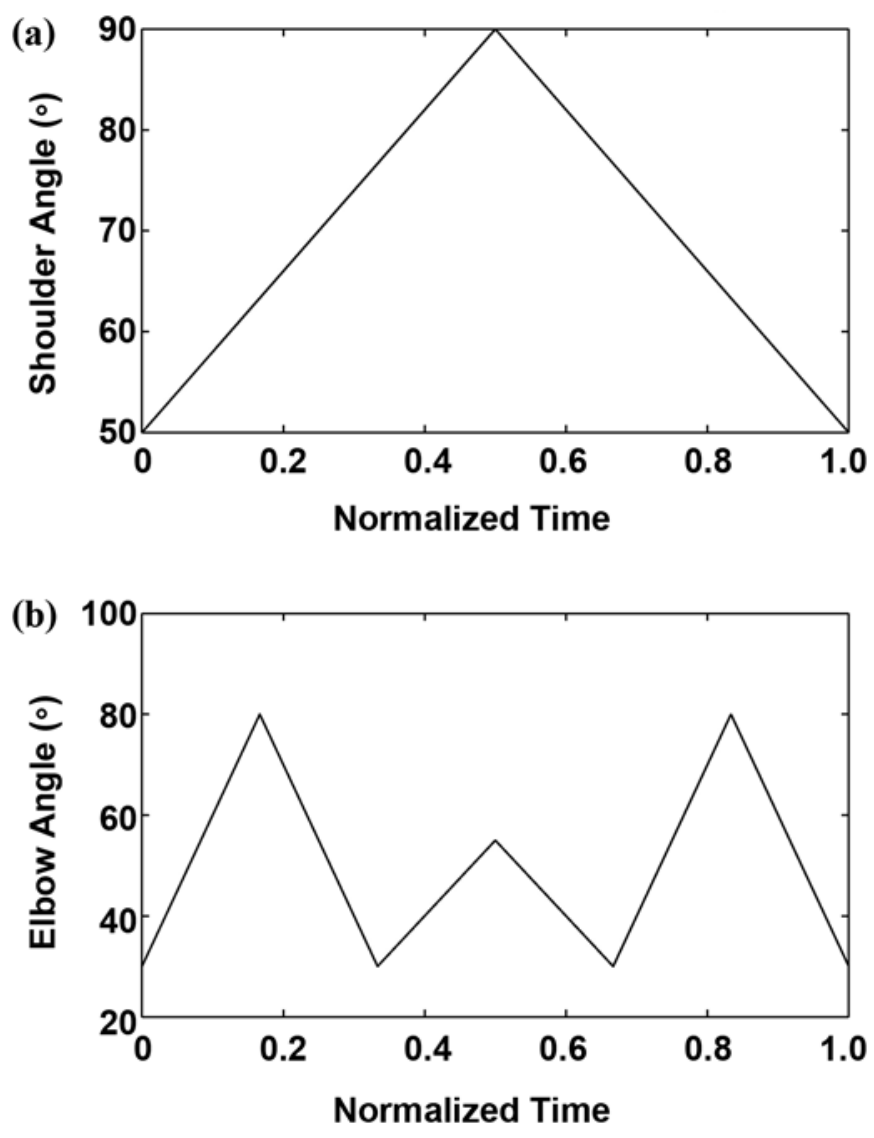

Figure 1.

Joint paths used in motor learning experiment: (a) shoulder elevation angle and (b) elbow flexion angle. two joints after stroke [20-23]. This configuration produced a complex, novel, 3-D movement that would require motor learning for mastery. Using a novel movement pattern is important for demonstrating measurable learning during the training. The main complexity of the path was in the elbow. Three extension and flexion movements of the elbow were performed in each task repetition. However, we made the amount of elbow flexion different between the top and bottom shoulder positions to avoid symmetry that would simplify the task. The arm was positioned at $30^{\circ}$ of internal rotation of the shoulder and with the wrist in the neural position. This produced movement that was not restricted to a single plane and further complicated the trajectory.

\section{ARMin III Robot}

All training and recall testing was performed in the ARMin III rehabilitation robot (Figure 2) [50,73]. The ARMin III is an exoskeleton robot with six active DOFs, which assist the patient with shoulder, elbow, and wrist movements. The ARMin III can measure the angle of and apply torque directly to each of these joints. We engaged the compensation for the robot's weight and viscous friction to decrease the impedance of the robot. Gravity and friction compensation for the robot arm is vital for minimizing the interaction forces required to move the robot in the "free" mode that is used in the recall trials for evaluating the trajectory learning. Although the ARMin III has

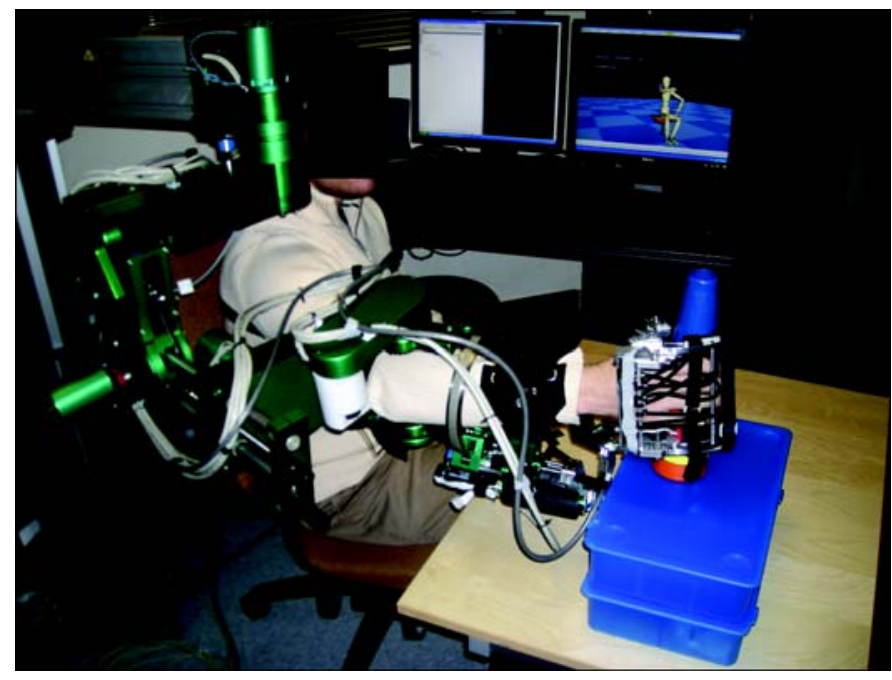

Figure 2.

ARMin III robot and passive hand device, HandSOME, being used in functional shelf task in time-independent functional training mode. 
a visual interface designed for patient feedback, as shown in the background of Figure 2, we did not use this interface in this study.

In the TIFT mode, the desired joint rotation direction is known at each point in the trajectory. This directional information allows the robot to provide feed-forward static friction compensation in addition to gravity and viscous friction compensation. The robot provides a small torque in the desired direction that is approximately equal to the static friction value determined experimentally. Although this torque does not move the robot, it decreases the amount of force required to initiate movement at the joint. This feed-forward compensation effectively doubles the force needed to initiate movement in the direction opposite to the desired direction. When the joint velocity is greater than a small value, this torque is set to zero and the viscous friction compensation is engaged. A complete description of this method and experimental determination of static and viscous friction of the ARMin III robot joints have been reported elsewhere [74]. The torque required to initiate movement at the elbow flexion and shoulder elevation joints of the robot was $0.39 \mathrm{Nm}$ [74].

\section{TIFT}

The TIFT mode was designed for retraining functional tasks after stroke but can be used for training any path. The mode can be controlled by any of the robot joints in any pairing combination. Although all the joints could be set as control joints, moving through the path with only the main joints used in the trajectory set as control joints is easiest. Usually, the two joints with the largest range of motion (ROM) during the task are chosen as control joints. For example, to put an object on a shelf, the main two movements are elbow extension and shoulder elevation. These are the joints that would be set as the default control joints for that task. The subject is required to appropriately coordinate the two control joints to progress along the trajectory. Haptic walls are provided at the control joints to constrain the subject to the proper interjoint coordination between the shoulder and elbow. If the proper shoulder-elbow coordination is performed, these haptic walls allow the subject to move through the trajectory at his or her own pace and without resistance or assistance from the robot. In the shelf task, the shoulder must be elevated and the elbow extended at the same time for proper completion of the task. The robot will not allow advancement in the trajectory if the subject first raises his or her shoulder and then extends his or her elbow in sequence. Advancement is also not allowed if simultaneous shoulder elevation and elbow flexion occur instead of elbow extension. If the ratio of shoulder elevation and elbow extension is within a desired window (desired ratio plus or minus a deadband), movement is allowed and the haptic walls guide the joints toward the correct ratio. In this way, the TIFT mode requires the subject to actively produce the proper joint coordination to move through the trajectory. While the subject navigates the two control joint trajectories, the other joints are moved along their desired trajectories with a proportional-derivative (PD) position feedback controller. Advancement at all joints, control and slaved, is coordinated through a global advancement parameter that assures normal limb kinematics during the task.

\section{Trajectory Progression with TIFT}

Joint angle paths for all joints move through the task and then back, with the same coordination, to the starting position as one repetition. The angle values over time for each joint were normalized between 0 and 1 to make the $\mathrm{ROM}$ of the joints easily variable with gains. The time dimension of these paths was also normalized between 0 and 1.

The global variable $G$ is defined as the current point and is the fraction of the trajectory completed. This variable begins at 0 and moves to 1 as the subject returns to the initial position. For all joints, the current $G$ value and the target joint angle paths determine a reference angle for each joint $\left(q_{\text {ref }}\right)$. The uncontrolled joints are servoed with a PD controller to $q_{\text {ref }}$. For control joints, haptic walls in front and behind the $q_{\text {ref }}$ are constructed with a $4^{\circ}$ deadband. Therefore, for a constant $G$, each control joint has $4^{\circ}$ of free play before hitting a wall. This $4^{\circ}$ deadband is wide enough for smooth unrestricted movement through the path when the subject is producing the correct joint coordination, but it will still keep the subject close to the correct joint kinematics when he or she is maneuvering through the joint-space walls. The current position $\left(q_{\mathrm{act}}\right)$ is used for calculating the single joint advancement variable, $g$, and provides a measure of that joint's location relative to its desired path. This calculation is not straightforward, as shown in Figure 3. Because of possible reversals in the joint path, a value of $q_{\text {act }}$ can be associated with multiple $g$ values. Therefore, the method relies on a linear approximation to calculate $\Delta g$ as a function of $q_{\mathrm{act}}, q_{\mathrm{ref}}$, and the joint angle for a 


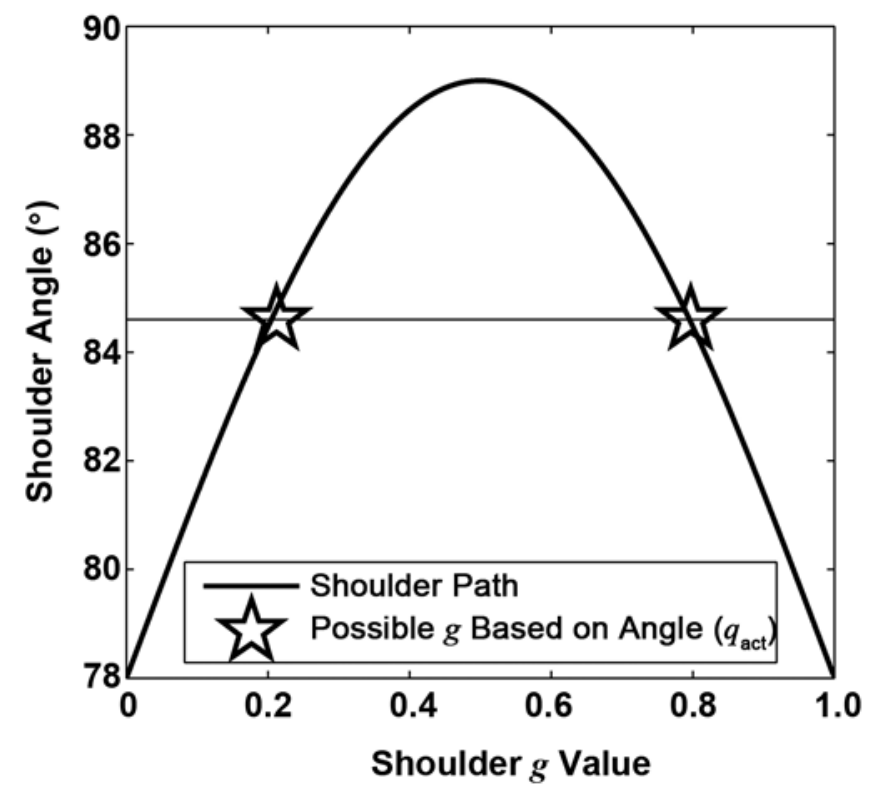

Figure 3.

Shoulder trajectory in shelf path: demonstration that $g$ (single-joint advancement variable) is not unique for given shoulder joint angle $\left(q_{\text {act }}\right)$.

2 percent advancement in the local $g$ value ( $\left.q_{\text {refplus }}\right)$. Figure 4 illustrates this algorithm and describes the special case in which the joint path reaches a plateau.

The change in $G$ is determined by adding the minimum progression of all of the control joints $(\Delta g)$ along the trajectory. The addition of the smallest $\Delta g$ to obtain the new $G$ guarantees that all the joints must progress together to complete the task. The new $G$ establishes new reference joint angles for all joints $\left(q_{\text {ref }}\right)$. Negative $\Delta g$ values are set to 0 to prevent subjects from moving backward along the trajectory. When the subject returns to the initial position, the $G$ value becomes 1 and is then reset to 0 so the subject can repeat the pattern as many times as desired.

\section{Boundary Walls for Trajectory}

We used the $g$ value of each control joint to determine the locations of boundaries for haptic walls in front and behind $q_{\text {ref. }}$ A deadband of $4^{\circ}$ provides a joint-space channel that the subject can move through to complete the trajectory without hitting a wall. The joint walls were defined with exponential stiffness as described in Figure 5, where $\tau$ is the boundary wall torque, $C$ is a constant that determines the stiffness of the wall, and $D$ is the dead-

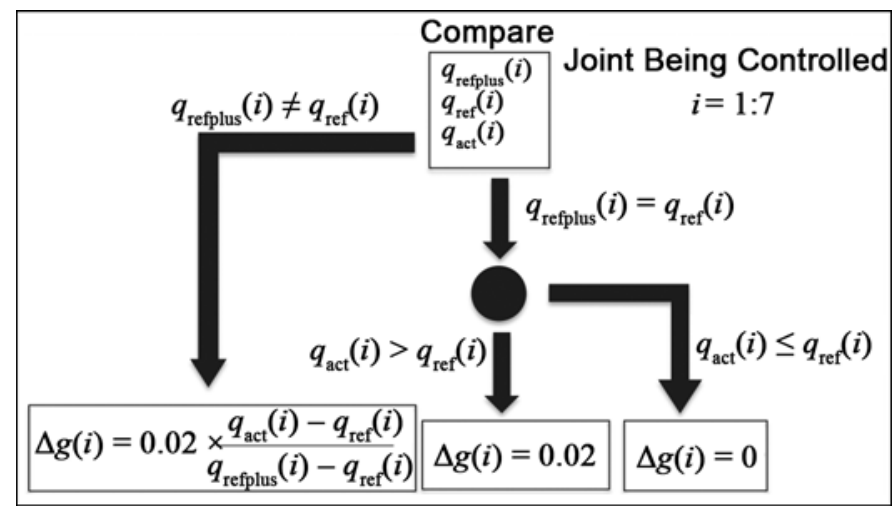

Figure 4.

Algorithm for calculation of change in single-joint advancement variable $\Delta g . q_{\text {act }}=$ current joint angle, $q_{\text {ref }}=$ reference joint angle on path, $q_{\text {refplus }}=$ reference joint angle for $2 \%$ advancement in $g$ (singlejoint advancement variable), $i=$ robot joint.

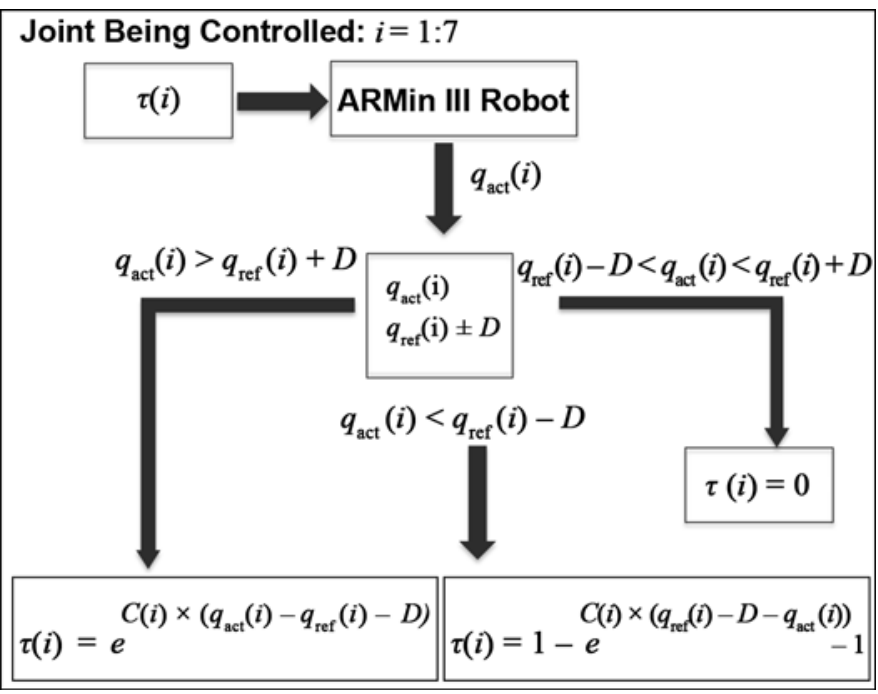

Figure 5.

Torque applied to ARMin III robot control joints based on their position relative to reference position on trajectory. $\tau=$ torque applied by robot, $q_{\text {act }}=$ current joint angle, $q_{\text {ref }}=$ reference joint angle, $q_{\text {refplus }}=$ reference joint angle for $2 \%$ advancement in $g$ (single-joint advancement variable), $D=$ deadband, $C=$ constant that determines stiffness of joint walls, $i=$ robot joint.

band angle. The wall stiffness constant, $C$, was tuned for each joint to ensure proper feedback and adherence to the $4^{\circ}$ deadband $\left(C_{\text {shoulder }}=1.5^{\circ-1}, C_{\text {elbow }}=1.2^{\circ-1}\right)$. Slaved joints were given a deadband of $0.4^{\circ}$ so some compliance would exist in the joints but they would still track their trajectory according to the progression of $G$. We applied an additional gain factor to convert the exponential terms 
into the torques applied by the motors $\left(K_{\text {shoulder }}=1.5 \mathrm{Nm}\right.$, $K_{\text {elbow }}=1 \mathrm{Nm}$ ). The torque applied when the subject is moving $1^{\circ}$ beyond the deadband of the shoulder is $3.48 \mathrm{Nm}$ in the TIFT mode. This torque provides a solid barrier to keep the subjects within the desired joint position range.

\section{TD Training, Visual Demonstration, and Recall Testing}

Two training modes were developed in conjunction with TIFT for examining the effectiveness of TIFT. TD training, visual demonstration, and TIFT were used as the training methods. TD training is commonly used for robotic therapy. The robot moves a subject's arm through the task using a PD feedback controller tuned for each joint so that small errors occur in joint positions relative to the ideal reference trajectory $\left(K_{\text {shoulder }}=62 \mathrm{Nm} /{ }^{\circ}\right.$, $K_{\text {elbow }}=5 \mathrm{Nm}^{\circ}$ ). The subject is asked to actively move along with the robot through the task. In visual demonstration, the subject stood behind the robot, as close as possible to the perspective of the stand-in person in the robot. The subject was then asked to watch the stand-in's arm as it was moved through the path by the robot. The subject was told not to move his or her arm as he or she learned the movement. The stand-in was used for visual demonstration training because visualizing arm joint position without a human arm in the exoskeleton robot was difficult. The robot used a stiff PD controller to move along the trajectory with minimal kinematic error, so the stand-in did not noticeably affect the trajectory. Therefore, the visual image of a human arm moving through the trajectory was consistent across the three training groups. As in the study by Liu et al., we used the visual demonstration group to examine the effectiveness of visual demonstration on learning a novel task for comparison with the haptic robot-assisted modes that provide both robotic guidance and visual demonstration [70].

For all subjects, trajectory recall was tested before and after each training block. In the recall phase, the subject was asked to repeat the trained shoulder-elbow trajectory three times in the robot while the other joints were locked in their appropriate positions. The elbow and shoulder of the robot were in "free" mode with minimal resistance to movement. The robot provided the best possible "free" mode by compensating for the robot's weight and viscous friction during recall. The most backdriveable joints (shoulder elevation, elbow flexion/extension) were chosen for the trajectory. Although robot inertia would affect the movements, the subjects controlled the speed of the recall movements and moved the robot at a self-selected velocity, which minimized the influence of robot inertia. Haptic walls were placed $1^{\circ}$ beyond the $\mathrm{ROM}$ of the shoulder in both directions. This kept the subjects within the ideal ROM of the shoulder and made for easier analysis of data. In all the modalities, a PD controller moved the robot to the initial position of the task before starting training or recall.

In both the TD training and visual demonstration modes, each repetition was completed in $12 \mathrm{~s}$. TIFT mode subjects were informed if they were going slower than the $12 \mathrm{~s}$ required to complete a single-task repetition in the TD training mode to avoid any possible advantage they could have from extended time learning the path. On average, the TIFT movement time was $13.1 \mathrm{~s}$ and not significantly different from the $12 \mathrm{~s}$ time in the TD group $(p=$ 0.09). The $12 \mathrm{~s}$ path time allowed a comfortable and smooth movement in the robot during the training modes. This relatively slow path encouraged similarly slow movement in the robot during recall attempts, which minimized inertial effects. The average subject movement time in recall was $12.25 \mathrm{~s}$, which was not significantly different from the $12 \mathrm{~s}$ demonstration speed $(p=0.60)$. For the entire experiment, the only visual feedback received by the subjects was looking at a human arm moving through the pattern (their own arm or the arm of the stand-in).

\section{Data Processing}

We calculated three performance metrics for each recall phase: joint error, slope error, and movement variability. Each recall consisted of three repetitions of the movement. The simplicity of the shoulder trajectory results in a unique desired elbow angle for each shoulder position. The shoulder ROM was divided into $1^{\circ}$ bins. For each bin, we determined the six time intervals when the shoulder angle was within this bin. The elbow angle was averaged within each of the six time intervals. We then averaged these six values of elbow angle to produce an estimate of the elbow angle associated with the corresponding shoulder angle. This resulted in the phase plane plots shown in Figure 6. We also calculated the standard deviation over these six elbow angle values, and used the mean of these standard deviations over the ROM of the shoulder as an estimate of movement variability. We then calculated the absolute value of the difference between the ideal reference elbow angle for each shoulder position and the recall elbow angle at that shoulder position. We then added these values across the ROM of the shoulder 


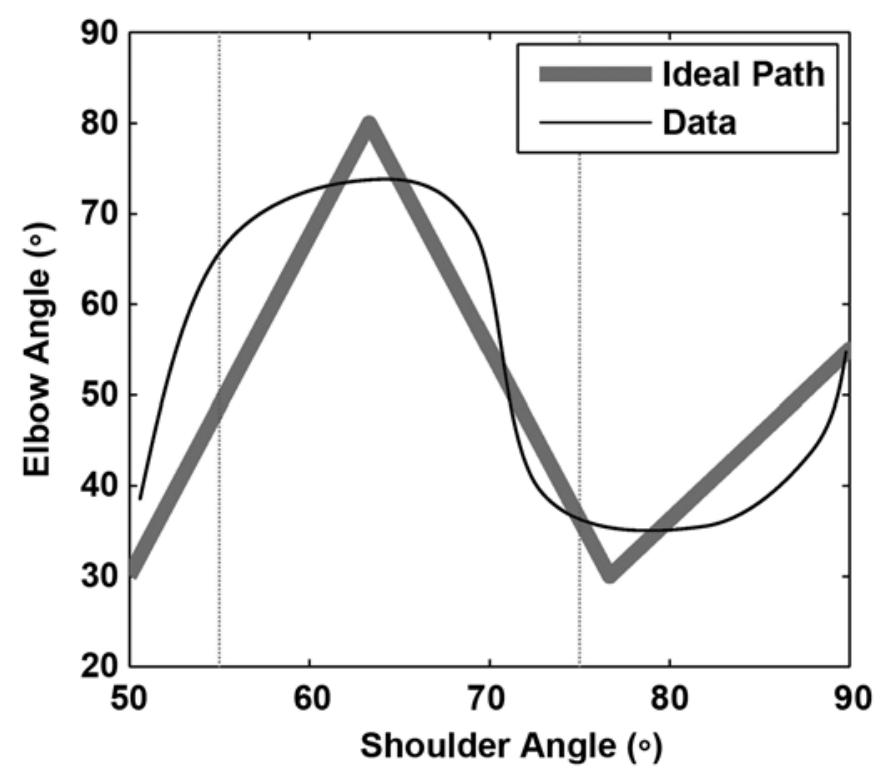

Figure 6.

Joint coordination pattern of shoulder and elbow in motor learning testing. Thick gray line is desired reference trajectory and thin black curve is typical actual trajectory. At shoulder angle of $55^{\circ}$, elbow should be at $49^{\circ}$. However, elbow is actually about $65^{\circ}$, an error of $16^{\circ}$. However, when shoulder is at $75^{\circ}$, elbow error is nearly 0 .

to provide the area between the reference and actual phase plane plots shown in Figure 6. We obtained the subject's joint error in the trajectory by dividing this error area by the ROM of the shoulder. The phase plane trajectory was then divided into three phases with different shoulder-elbow movement ratios. We calculated the slopes of the subject recall data within each phase. We calculated the slope error as the absolute value of the difference between actual slope and ideal slope for the corresponding phase. The mean slope error over the trajectory was the mean of the slope errors over the three trajectory phases. We performed the same procedure on the training data and computed average metrics for each training block.

We used univariate analysis of variance (ANOVA) to test for group differences at baseline in age and the performance metrics and chi-square tests to test for group differences in sex. We used repeated measures ANOVA (within-subjects factor of block, between-subjects factor of group) to assess group differences in the pattern of learning across training as well as recall trials.

\section{RESULTS}

Thirty-seven subjects completed the training. Outliers were defined as those subjects with baseline performance errors greater than the upper quartile $+1.5 \times$ interquartile range or less than the lower quartile $-1.5 \times$ interquartile range. Two subjects had very large initial recall errors and were determined to be outliers. Deletion of these two poor performing subjects significantly improved the between-group balance in baseline performance. The following analysis is limited to the remaining 35 subjects (12 in the vision group, 14 in the TIFT group, and 9 in the TD group). The mean \pm standard deviation age was $33 \pm$ 13 years, and ANOVA found no group differences in age $(p=0.12)$. The ratio of male to female subjects did not differ from a 1:1 ratio in any of the groups $(p>0.1)$. Two subjects were left-hand dominant and one subject was ambidextrous.

Figure 7 shows the typical change in the training pattern in a TIFT subject from the first to the eighth block. In the first block, the subject got stuck in the path repeatedly, and two distinct paths were visible for different directions of movement, showing that the subject was relying heavily on the walls. However, in the eighth block, the variability had decreased and the movement had become smoother. Repeated measures ANOVA of TIFT and TD training data showed a significant group $\times$ block number interaction in error $(p=0.002)$ and variability $(p=0.04)$. Subjects who received TIFT had significant reductions in error $(p<0.001)$, while TD trained subjects did not reduce error during training ( $p=$ 0.76) (Figure 8(a)). Movement variability decreased significantly over training in both the TIFT $(p=0.009)$ and TD training modes $(p=0.02)$. Mean reductions in error and variability in the TIFT group were 18.7 and 20.9 percent, respectively, while mean reductions in error and variability in the TD training group were 0.48 and 23.4 percent. For slope error, the block factor and the group $\times$ block interaction were not significant $(p>0.60)$.

A similar result can be seen in the robot-applied elbow guidance torque during training (Figure 8(b)). The mean elbow torques for the TD and TIFT modes were not significantly different for the initial passive movement trials $(p=0.10)$ or in the first training block $(p=0.56)$. However, the pattern of change in elbow torque across training blocks was significantly different between groups (group $\times$ block number interaction, $p<0.001$ ). The applied torque decreased significantly across blocks 

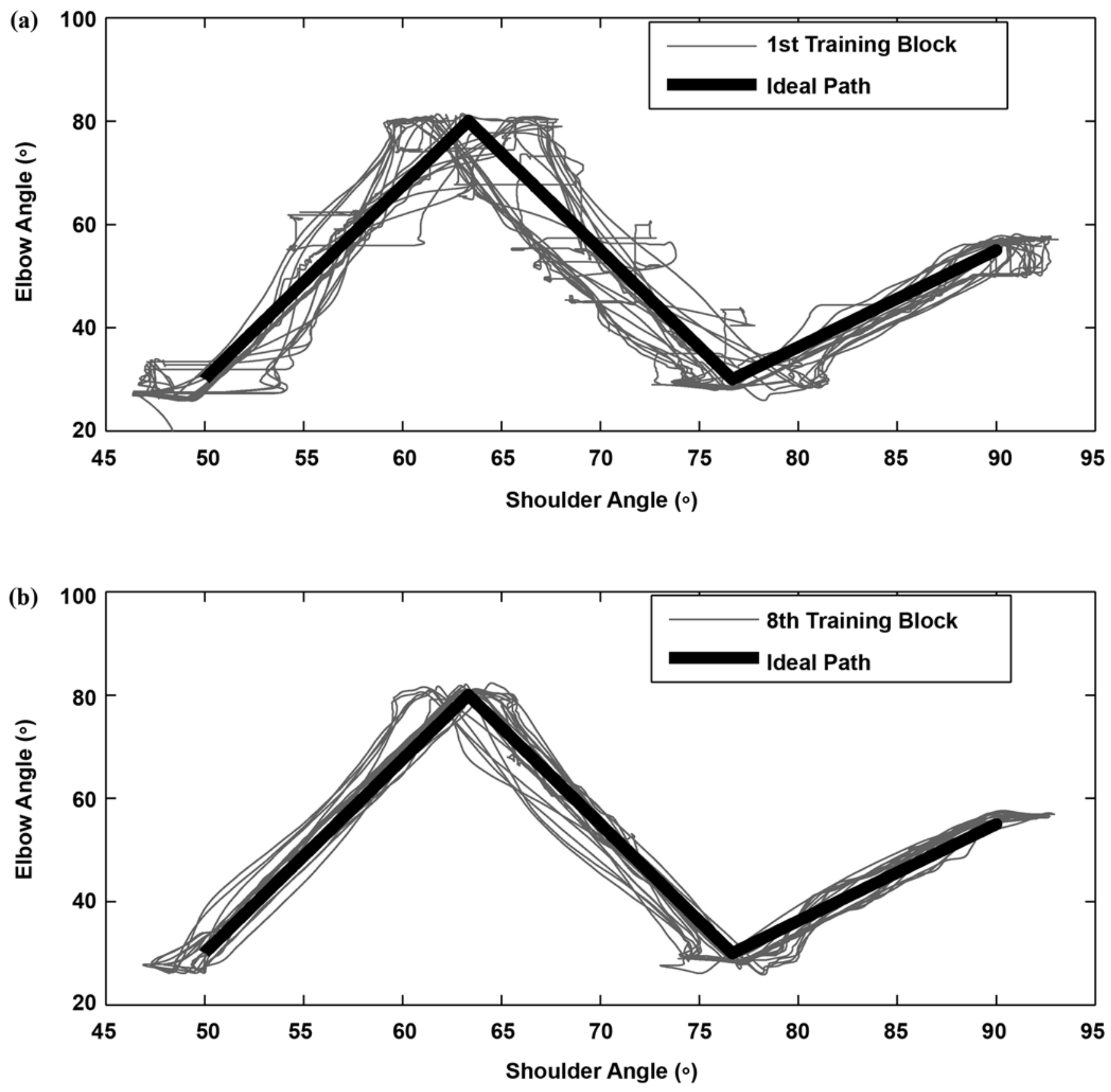

Figure 7.

Joint coordination pattern of shoulder and elbow during time-independent functional training in a typical subject: (a) first training block and (b) eighth training block. Trajectories were disjointed in first training block but improved in smoothness by last training block.

in the TIFT mode $(p<0.001)$, but not in the TD training mode $(p=0.67)$. Applied elbow torque during passive movement was $5.1 \pm 0.2 \mathrm{Nm}$ in the TD training group, significantly greater than during the first training block $(p=0.02)$, demonstrating that subjects were attempting to move with the robot during the TD training. Because the TD subjects were trying to move with the robot, one would expect a reduction in applied elbow torque as they learned the trajectory. The minimum possible robotapplied torque for the TD training mode is equal to the 

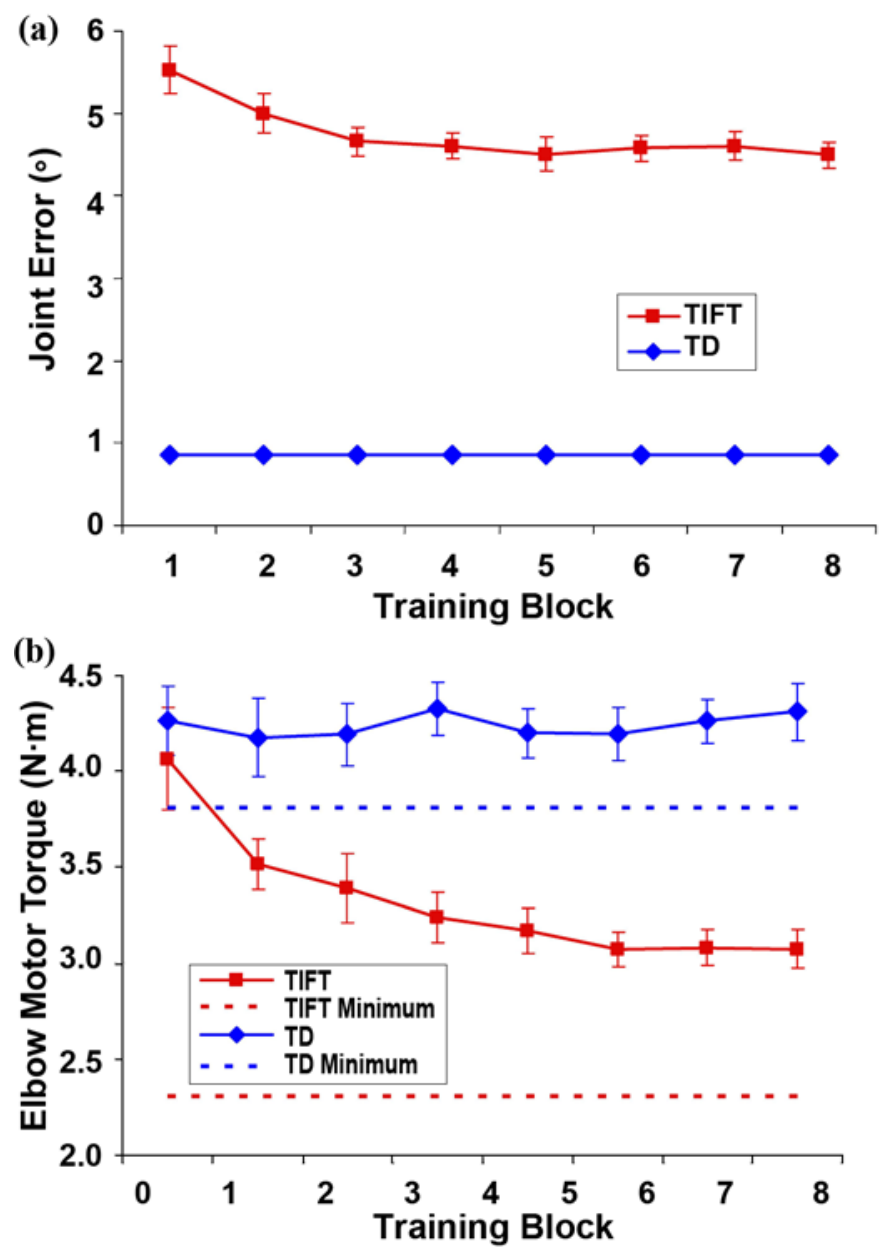

Figure 8.

(a) Mean error reductions during training blocks for time-independent functional training (TIFT) and time-dependent (TD) groups with standard error bars. Joint error decreases over 8 training blocks in TIFT subjects but is unchanged in TD subjects. (b) Mean elbow torque applied by robot during training blocks for TIFT and TD groups with standard error bars. Minimum possible torque for TD is shown, which is elbow torque required to move through path without human arm in robot. This corresponds to best possible performance in TD training mode. Minimum possible TIFT value is also shown, which is applied torque if subject moves through trajectory perfectly without hitting any haptic walls.

applied torque without a subject's arm in the robot. This represents the best possible subject performance, when the subject moves along with the robot perfectly and no interaction forces are applied between the robot and human. However, the TD group did not show any decrease in torque toward this minimum value during training. The minimum possible elbow torque value for the TIFT is the torque the robot applies to compensate for robot weight and friction when the subject moves through the path perfectly without hitting the haptic guidance walls. TIFT subjects showed a steady decrease in robot-applied elbow torque across the training blocks, although they did not reach the minimum torque value. We did not examine shoulder torque trends because of changes between subjects in the spring and cable system that assists with gravity compensation. The spring parameters are incorporated into the shoulder motor's gravity compensation algorithm, so the motor torque applied to each subject differed based on the specific spring parameters used during testing [75].

Initial recall data showed no group differences in baseline error values $(p=0.36)$. Figure 9 shows the learning curves for the three groups in the joint error metric. Mean reductions in joint error between the first and ninth recall tests across all subjects was 35 percent. We performed repeated measures ANOVA to determine group differences in the pattern of learning over the nine recall blocks. The block factor was significant in joint error $(p<0.001)$, slope error $(p=0.02)$, and variability $(p<0.001)$, indicating that all groups improved in all metrics during the recall blocks. The group $\times$ block interactions were not significant in any of these metrics $(p>$ $0.20)$. This result indicates that all three groups learned with a similar pattern.

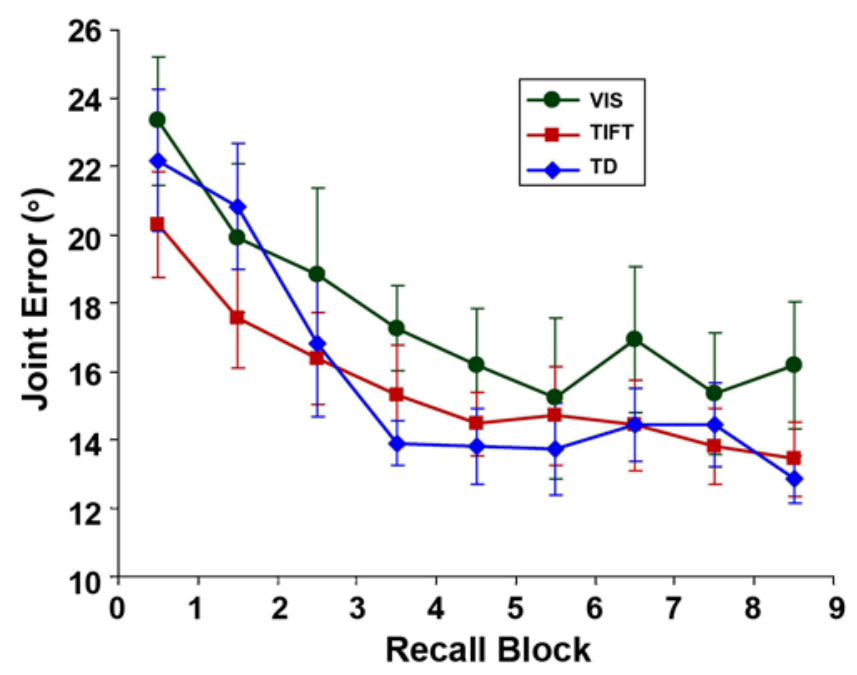

Figure 9.

Joint error reductions during recall blocks with standard error bars. Significant learning was present in all groups, but no group differences were present in learning rates or amount of error reduction. VIS = visual demonstration, TIFT = time-independent functional training, TD = time-dependent training. 


\section{DISCUSSION}

We presented details of the TIFT mode for training of interjoint coordination as well as a motor learning study to provide initial validation of the modality. During the recall tests, all subject groups significantly reduced joint error, slope error, and variability. However, the pattern of learning did not differ between groups. Thus, all groups performed equivalently in recall despite significantly better error and torque reductions during TIFT than during TD training. Analysis of the training data showed evidence of learning in the TIFT group, as subjects reduced joint error and movement variability in the robot over 80 repetitions. In contrast, the subjects who received TD training did not reduce error during the training. Similar results were seen in robot-applied elbow torque, with significant torque reductions during TIFT but no change in torque during TD training.

Learning the kinematics of a complex novel movement is possibly dominated by vision, because the additional haptic guidance provided to the TIFT and TD groups did not produce measurable benefits compared with only visual presentation of the trajectory. This result is similar to the findings of Liu et al., who reported no difference in learning of a 3-D endpoint trajectory between visual demonstration and TD training [70]. The powerful role of the vision system in motor learning is becoming apparent, with studies showing similar brain activation and plastic adaptation between repetitive practice and action observation [71]. Stroke therapy consisting of motor imagery combined with physical therapy improved functional task performance compared with time-matched physical therapy alone [76]. Thus, the presence of vision information possibly overshadowed potential differences between the TD and TIFT modes. In future work, we plan to perform experiments with vision occluded. This research may uncover differences between TIFT and TD, as subjects will be forced to rely entirely on haptic and proprioceptive information to learn the novel trajectories.

Examination of the training data suggests advantages of the TIFT mode compared with the TD training mode, which may lead to improved outcomes in stroke populations. TIFT promoted learning, with the error and guiding elbow torque decreasing significantly during the training. This learning effect may be related to the gradual reduction of interaction forces observed when subjects are exposed to endpoint "tunnels" during learning of novel dynamic environments [77-78]. In contrast, TD subjects did not vary their movement strategy during training as the error and guiding elbow joint torque remained constant throughout, despite significant learning of the trajectory in recall trials. Because the instruction to TD subjects was to "move with the robot" and the trajectory was complex and novel, one would have expected errors and elbow torque to reduce during training as subjects learned the trajectory. If common mechanisms subserve motor learning and recovery of motor control after stroke, then a training mode that promotes decreases in training errors with practice would be hypothesized to be more effective in stroke rehabilitation than a mode in which subjects do not change strategy with repeated trials. A second potential advantage of the TIFT is that it allows for much greater kinematic variability during training, which has been hypothesized to have advantages to fixed trajectory robotic training with small kinematic errors [79-81]. Mean errors during TIFT were more than five times larger than those for TD training. While larger errors in the TD training mode could have been achieved with smaller gains in the position feedback controller, this would not likely have promoted the learning seen in the TIFT data. Therefore, TIFT promotes voluntary exploration of a fairly large kinematic workspace, while the robot rewards correct movements with trajectory advancement and punishes incorrect movements by not allowing advancement.

Despite these potential advantages of TIFT over TD training, our recall data showed that TIFT was not better than TD in promoting learning of a complex trajectory in nondisabled subjects. A potential drawback of the TIFT in this learning task is the much larger kinematic errors that occurred during training compared with the other modes. Furthermore, learning in TIFT was disjointed early in the training, with subjects often hitting the path walls, stopping and trying several strategies before determining the correct shoulder-elbow coordination needed to advance within the path. Nevertheless, for stroke rehabilitation, we believe further study into assistance modes such as TIFT is needed, given the recent negative findings in robots that have used the TD training mode [4243] and the evidence that passive movement training does not improve motor control [82-83]. For example, Bluteau et al. found that in a drawing task, haptic guidance with a position-based controller similar to our TD training mode was inferior to a force-based controller for motor learning [84]. 
Although the neural control mechanisms of locomotion and upper-limb function differ greatly and may require different robotic control algorithms, the concept of promoting patient interaction and maintaining proper joint coordination is important in both areas of therapy and has motivated parallel development of similar control modes for both upper and lower limbs. The recently published article by Duschau-Wicke et al. discusses a new modality for the Lokomat ${ }^{\circledR}$ (Hocoma AG, Volketswil, Switzerland) assistive robot for gait training [57]. This modality has some similarities to TIFT in that it uses joint space haptic walls to maintain the hip and knee within a desired joint space trajectory. The key difference between this implementation and the TIFT mode is the algorithm for advancement within the trajectory (Figure 10). In the Duschau-Wicke method, when the limb is moved to a certain point in joint space, the current location along the desired trajectory (which determines the location of the haptic walls) is advanced to the point on the desired trajectory closest (in the Euclidean sense) to the current limb position. However, as shown in Figure 10, in many cases, this approach allows advancement along the trajectory to be driven by rotating one joint in the correct direction, while the other joint is pushed along by the robot. Therefore, no coordinated movement of the two joints is required to advance. In the TIFT mode, movement of only one joint does not allow one to advance in the trajectory; proper interjoint coordination is required for advancing. Thus, the TIFT mode is purely passive in that no energy can be injected into the limb. In contrast, the DuschauWicke method allows for significant energy to be transferred to the limb by the robot.

We acknowledge that the Duschau-Wicke method will ease advancement, and some subjects with stroke may not be able to advance in the TIFT mode. However, we were targeting interjoint coordination specifically when we designed the TIFT mode, and based on motor learning principles, we did not want to allow trajectory advancement unless the proper coordination was produced. Furthermore, TIFT maintains normal timing between proper muscle activation patterns and movement. Electrophysiology experiments have demonstrated that afferent feedback can facilitate plasticity in the motor system if it arrives synchronously with ongoing motor output [59-60]. This has motivated a number of robotic strategies to assure proper timing between effort and movement, including movement of the contralateral limb to control movement of the paretic limb in bilateral tasks [32,85-86] and EMG-controlled movement [83,8788]. The TIFT mode assures proper timing between effort and movement by presenting a passive environment to the limb, such that no energy is injected into the limb. Proper timing cannot be guaranteed in systems that inject energy into the limb. However, the drawback of a passive environment is that some subjects with stroke will not be able to complete movements in the TIFT mode. In these subjects, a graded assistance level can be used that is controlled adaptively to prevent slacking behavior by patients [89]. This approach appears promising for retraining reaching movements after stroke [90-93].

Several adaptations to the TIFT mode have been implemented for future research with the stroke population. We have implemented TIFT into functional ADL tasks, such as putting an object on a shelf, pouring from a pitcher, and sorting objects. This effort was made possible

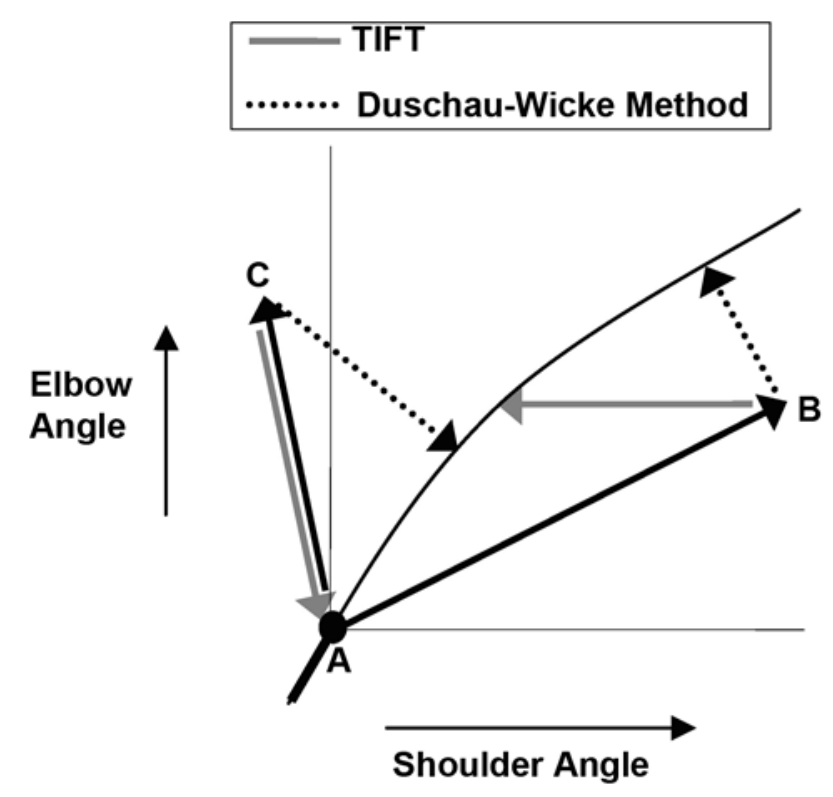

Figure 10.

Contrast between time-independent functional training (TIFT) and Duschau-Wicke methods for trajectory advancement. Current point on trajectory is A. Points B and C are two possible movements in joint space. Gray and dotted arrows point to resulting advancement points on trajectory for two methods. Because current point on trajectory determines location of haptic walls, energy injection into limb is possible in Duschau-Wicke method, while TIFT mode is passive. Note that for point C, Duschau-Wicke method allows advancement along trajectory even when shoulder is rotating in wrong direction. Since TIFT method does not allow moving backward in trajectory, movement to point $\mathrm{C}$ does not change current point on trajectory. TIFT mode only allows progression for movements to right and above thin black lines. 
by incorporating a passive hand device (HandSOME) [94-95]. The ARMin III, in conjunction with the HandSOME device, helps patients manipulate real or virtual objects during training to increase patient interaction during ADL functional training. Training in nonfunctional, low-DOF tasks is also possible and may be more effective than training in complex, high-DOF ADLs [96]. A visual interface helps subjects with stroke understand the TIFT haptic guidance by providing visual cues on the required direction of joint rotation for task completion in the robot. Graded human arm gravity compensation has been added to the TIFT mode to help patients overcome weakness and abnormal synergies. This arm gravity compensation can be varied from 0 to 100 percent of the arm's weight to encourage the subject but still maximize his or her effort during training.

\section{CONCLUSIONS}

The trajectory recall data of this motor learning study showed that provision of haptic and proprioceptive information did not improve learning of a complex trajectory above what was possible with vision information alone. We are currently repeating these experiments with vision removed to directly compare the TIFT and TD training modes. We acknowledge that currently we have no empirical evidence to recommend use of TIFT over the more easily implemented TD training mode. However, we believe further study of the TIFT mode is warranted based on the theoretical advantages of TIFT and subject performance in the training trials. Compared with TD training, TIFT has several theoretical advantages: minimally interfering with the input/output map between correct muscle activation and movement, allowing greater kinematic variability during training, and requiring subjects to produce proper interjoint coordination to advance within the trajectory. We also observed advantages of TIFT in the training data. TIFT had lower interaction forces between the robot and human arm than those of TD training, which shows that the human arm was contributing more to the movements during TIFT than during TD training. Also, error and assistance forces gradually reduced during TIFT, but no changes occurred in these metrics during TD training.

\section{ACKNOWLEDGMENTS}

\section{Author Contributions:}

Study concept and design: P. S. Lum, E. B. Brokaw, T. Nef, T. Murray. Acquisition of data: E. B. Brokaw.

Analysis and interpretation of data: P. S. Lum, E. B. Brokaw.

Drafting of manuscript: P. S. Lum, E. B. Brokaw.

Critical revision of manuscript for important intellectual content:

P. S. Lum, E. B. Brokaw, T. Nef, T. Murray.

Statistical analysis: P. S. Lum, E. B. Brokaw.

Obtaining funding: P. S. Lum.

Administrative, technical, or material support: P. S. Lum.

Study coordination and supervision: P. S. Lum.

Financial Disclosures: The authors have declared that no competing interests exist.

Funding/Support: This material was based on work supported in part by the U.S. Army Medical Research and Materiel Command,

grant W81XWH-05-1-0160, and the Department of Veterans Affairs, grant B4719R.

Institutional Review: All experiments were approved by the Office of Research Integrity of the Medstar Health Research Institute, Hyattsville, Maryland.

Participant Follow-Up: The authors plan to inform participants of the publication of this study.

\section{REFERENCES}

1. Lloyd-Jones D, Adams R, Carnethon M, De Simone G, Ferguson TB, Flegal K, Ford E, Furie K, Go A, Greenlund K, Haase N, Hailpern S, Ho M, Howard V, Kissela B, Kittner S, Lackland D, Lisabeth L, Marelli A, McDermott M, Meigs J, Mozaffarian D, Nichol G, O’Donnell C, Roger V, Rosamond W, Sacco R, Sorlie P, Stafford R, Steinberger J, Thom T, Wasserthiel-Smoller S, Wong N, Wylie Rosett J, Hong Y; American Heart Association Statistics Committee and Stroke Statistics Subcommittee. Heart disease and stroke statistics - 2009 update: A report from the American Heart Association Statistics Committee and Stroke Statistics Subcommittee. Circulation. 2009;119(3):480-86.

[PMID: 19171871]

DOI:10.1161/CIRCULATIONAHA.108.191259

2. Reding MJ. A model stroke classification scheme and its use in outcome research. Stroke. 1990;21(9 Suppl):II35-37. [PMID: 2399548]

3. Mayo NE. Epidemiology and recovery. Phys Med Rehabil State Art Rev. 1993;7:27-42.

4. Dam M, Tonin P, Casson S, Ermani M, Pizzolato G, Iaia V, Battistin L. The effects of long-term rehabilitation therapy on poststroke hemiplegic patients. Stroke. 1993;24(8):1186-91. [PMID: 8342195]

5. Mayo NE, Wood-Dauphinee S, Côté R, Durcan L, Carlton J. Activity, participation, and quality of life 6 months poststroke. Arch Phys Med Rehabil. 2002;83(8):1035-42. 
[PMID: 12161823]

DOI:10.1053/apmr.2002.33984

6. Lai SM, Studenski S, Duncan PW, Perera S. Persisting consequences of stroke measured by the Stroke Impact Scale. Stroke. 2002;33(7):1840-44. [PMID: 12105363]

DOI:10.1161/01.STR.0000019289.15440.F2

7. Nichols-Larsen DS, Clark PC, Zeringue A, Greenspan A, Blanton S. Factors influencing stroke survivors' quality of life during subacute recovery. Stroke. 2005;36(7):1480-84. [PMID: 15947263] DOI:10.1161/01.STR.0000170706.13595.4f

8. Dromerick AW, Lang CE, Birkenmeier R, Hahn MG, Sahrmann SA, Edwards DF. Relationships between upper-limb functional limitation and self-reported disability 3 months after stroke. J Rehabil Res Dev. 2006;43(3):401-8. [PMID: 17041825] DOI:10.1682/JRRD.2005.04.0075

9. Bohannon RW, Warren ME, Cogman KA. Motor variables correlated with the hand-to-mouth maneuver in stroke patients. Arch Phys Med Rehabil. 1991;72(9):682-84. [PMID: 1859265]

10. Zackowsk KM, Dromerick AW, Sahrmann SA, Thach WT, Bastian AJ. How do strength, sensation, spasticity and joint individuation relate to the reaching deficits of people with chronic hemiparesis? Brain. 2004;127(Pt 5):1035-46.

[PMID: 14976070]

DOI:10.1093/brain/awh116

11. Gowland C, DeBruin H, Basmajian JV, Plews N, Burcea I. Agonist and antagonist activity during voluntary upperlimb movement in patients with stroke. Phys Ther. 1992; 72(9):624-33. [PMID: 1508970]

12. Lum PS, Patten C, Kothari D, Yap R. Effects of velocity on maximal torque production in poststroke hemiparesis. Muscle Nerve. 2004;30(6):732-42. [PMID: 15468340] DOI:10.1002/mus.20157

13. Dipietro L, Krebs HI, Fasoli SE, Volpe BT, Stein J, Bever C, Hogan N. Changing motor synergies in chronic stroke. J Neurophysiol. 2007;98(2):757-68. [PMID: 17553941] DOI:10.1152/jn.01295.2006

14. Cirstea MC, Mitnitski AB, Feldman AG, Levin MF. Interjoint coordination dynamics during reaching in stroke. Exp Brain Res. 2003;151(3):289-300. [PMID: 12819841] DOI:10.1007/s00221-003-1438-0

15. Reisman DS, Scholz JP. Workspace location influences joint coordination during reaching in post-stroke hemiparesis. Exp Brain Res. 2006;170(2):265-76. [PMID: 16328275] DOI:10.1007/s00221-005-0209-5

16. Beer RF, Dewald JP, Rymer WZ. Deficits in the coordination of multijoint arm movements in patients with hemiparesis: Evidence for disturbed control of limb dynamics. Exp Brain Res. 2000;131(3):305-19. [PMID: 10789946] DOI:10.1007/s002219900275
17. Rohrer B, Fasoli S, Krebs HI, Hughes R, Volpe B, Frontera WR, Stein J, Hogan N. Movement smoothness changes during stroke recovery. J Neurosci. 2002;22(18):8297-304. [PMID: 12223584$]$

18. Krebs HI, Aisen ML, Volpe BT, Hogan N. Quantization of continuous arm movements in humans with brain injury. Proc Natl Acad Sci U S A. 1999;96(8):4645-49. [PMID: 10200316] DOI:10.1073/pnas.96.8.4645

19. Van Vliet PM, Sheridan MR. Coordination between reaching and grasping in patients with hemiparesis and healthy subjects. Arch Phys Med Rehabil. 2007;88(10):1325-31. [PMID: 17908577] DOI:10.1016/j.apmr.2007.06.769

20. Sukal TM, Ellis MD, Dewald JP. Shoulder abductioninduced reductions in reaching work area following hemiparetic stroke: Neuroscientific implications. Exp Brain Res. 2007;183(2):215-23. [PMID: 17634933]

DOI:10.1007/s00221-007-1029-6

21. Dewald JP, Beer RF. Abnormal joint torque patterns in the paretic upper limb of subjects with hemiparesis. Muscle Nerve. 2001;24(2):273-83. [PMID: 11180211] DOI:10.1002/1097-4598(200102)24:2<273::AIDMUS130>3.0.CO;2-Z

22. Sangani SG, Starsky AJ, McGuire JR, Schmit BD. Multijoint reflexes of the stroke arm: Neural coupling of the elbow and shoulder. Muscle Nerve. 2007;36(5):694-703. [PMID: 17628498] DOI:10.1002/mus.20852

23. Lum PS, Burgar CG, Shor PC. Evidence for strength imbalances as a significant contributor to abnormal synergies in hemiparetic subjects. Muscle Nerve. 2003;27(2):211-21. [PMID: 12548529] DOI:10.1002/mus.10305

24. Ellis MD, Holubar BG, Acosta AM, Beer RF, Dewald JP. Modifiability of abnormal isometric elbow and shoulder joint torque coupling after stroke. Muscle Nerve. 2005;32(2): 170-78. [PMID: 15880629] DOI:10.1002/mus.20343

25. Lum PS, Mulroy S, Amdur RL, Requejo P, Prilutsky BI, Dromerick AW. Gains in upper extremity function after stroke via recovery or compensation: Potential differential effects on amount of real-world limb use. Top Stroke Rehabil. 2009;16(4):237-53. [PMID: 19740730]

DOI:10.1310/tsr1604-237

26. Krakauer JW. Motor learning: Its relevance to stroke recovery and neurorehabilitation. Curr Opin Neurol. 2006;19(1): 84-90. [PMID: 16415682] DOI:10.1097/01.wco.0000200544.29915.cc

27. Roby-Brami A, Feydy A, Combeaud M, Biryukova EV, Bussel B, Levin MF. Motor compensation and recovery for reaching in stroke patients. Acta Neurol Scand. 2003; 
107(5):369-81. [PMID: 12713530$]$

DOI:10.1034/j.1600-0404.2003.00021.x

28. Michaelsen SM, Luta A, Roby-Brami A, Levin MF. Effect of trunk restraint on the recovery of reaching movements in hemiparetic patients. Stroke. 2001;32(8):1875-83.

[PMID: 11486120]

29. Michaelsen SM, Dannenbaum R, Levin MF. Task-specific training with trunk restraint on arm recovery in stroke: Randomized control trial. Stroke. 2006;37(1):186-92.

[PMID: 16339469] DOI:10.1161/01.STR.0000196940.20446.c9

30. Volpe BT, Huerta PT, Zipse JL, Rykman A, Edwards D, Dipietro L, Hogan N, Krebs HI. Robotic devices as therapeutic and diagnostic tools for stroke recovery. Arch Neurol. 2009;66(9):1086-90. [PMID: 19752297] DOI:10.1001/archneurol.2009.182

31. Riener R, Nef T, Colombo G. Robot-aided neurorehabilitation of the upper extremities. Med Biol Eng Comput. 2005; 43(1):2-10. [PMID: 15742713] DOI:10.1007/BF02345116

32. Lum PS, Burgar CG, Shor PC, Majmundar M, Van der Loos M. Robot-assisted movement training compared with conventional therapy techniques for the rehabilitation of upper-limb motor function after stroke. Arch Phys Med Rehabil. 2002;83(7):952-59. [PMID: 12098155]

DOI:10.1053/apmr.2001.33101

33. Lum PS, Burgar CG, Van der Loos M, Shor PC, Majmundar M, Yap R. MIME robotic device for upperlimb neurorehabilitation in subacute stroke subjects: A followup study. J Rehabil Res Dev. 2006;43(5):631-42.

[PMID: 17123204] DOI:10.1682/JRRD.2005.02.0044

34. Kahn LE, Lum PS, Rymer WZ, Reinkensmeyer DJ. Robotassisted movement training for the stroke-impaired arm: Does it matter what the robot does? J Rehabil Res Dev. 2006;43(5):619-30. [PMID: 17123203]

DOI:10.1682/JRRD.2005.03.0056

35. Reinkensmeyer DJ, Kahn LE, Averbuch M, McKennaCole A, Schmit BD, Rymer WZ. Understanding and treating arm movement impairment after chronic brain injury: Progress with the ARM Guide. J Rehabil Res Dev. 2000; 37(6):653-62. [PMID: 11321001]

36. Aisen ML, Krebs HI, Hogan N, McDowell F, Volpe BT. The effect of robot-assisted therapy and rehabilitative training on motor recovery following stroke. Arch Neurol. 1997; 54(4):443-46. [PMID: 9109746]

37. Krebs HI, Hogan N, Volpe BT, Aisen ML, Edelstein L, Diels C. Overview of clinical trials with MIT-MANUS: A robot-aided neuro-rehabilitation facility. Technol Health Care. 1999;7(6):419-23. [PMID: 10665675]

38. Prange GB, Jannink MJ, Groothuis-Oudshoorn CG, Hermens HJ, IJzerman MJ. Systematic review of the effect of robot-aided therapy on recovery of the hemiparetic arm after stroke. J Rehabil Res Dev. 2006;43(2):171-84.

[PMID: 16847784]

DOI:10.1682/JRRD.2005.04.0076

39. Mehrholtz J, Platz T, Kugler J, Pohl M. Electromechanical and robot-assisted arm training for improved arm function and activities of daily living after stroke. Cochrane Database Syst Rev. 2008;4:CD006876. [PMID: 18843735$]$

40. Kwakkel G, Kollen BJ, Krebs HI. Effects of robot-assisted therapy on upper limb recovery after stroke: A systematic review. Neurorehabil Neural Repair. 2008;22(2):111-21.

[PMID: 17876068]

DOI:10.1177/1545968307305457

41. Lo AC, Guarino PD, Richards LG, Haselkorn JK, Wittenberg GF, Federman DG, Ringer RJ, Wagner TH, Krebs HI, Volpe BT, Bever CT Jr, Bravata DM, Duncan PW, Corn BH, Maffucci AD, Nadeau SE, Conroy SS, Powell JM, Huang GD, Peduzzi P. Robot-assisted therapy for longterm upper-limb impairment after stroke. N Engl J Med. 2010;362(19):1772-83. [PMID: 20400552]

DOI:10.1056/NEJMoa0911341

42. Hornby TG, Campbell DD, Kahn JH, Demott T, Moore JL, Roth HR. Enhanced gait-related improvements after therapist- versus robotic-assisted locomotor training in subjects with chronic stroke: A randomized controlled study. Stroke. 2008;39(6):1786-92. [PMID: 18467648]

DOI:10.1161/STROKEAHA.107.504779

43. Hidler J, Nichols D, Pelliccio M, Brady K, Campbell DD, Kahn JH, Hornby TG. Multicenter randomized clinical trial evaluating the effectiveness of the Lokomat in subacute stroke. Neurorehabil Neural Repair. 2009;23(1):5-13.

[PMID: 19109447]

DOI:10.1177/1545968308326632

44. Burgar CG, Lum PS, Shor PC, Machiel Van der Loos HF. Development of robots for rehabilitation therapy: The Palo Alto VA/Stanford experience. J Rehabil Res Dev. 2000; 37(6):663-73. [PMID: 11321002]

45. Banala SK, Kim SH, Agrawal SK, Scholz JP. Robot assisted gait training with active leg exoskeleton (ALEX). IEEE Trans Neural Syst Rehabil Eng. 2009;17(1):2-8.

[PMID: 19211317]

DOI:10.1109/TNSRE.2008.2008280

46. Lum PS, Burgar CG, Shor PC. Evidence for improved muscle activation patterns after retraining of reaching movements with the MIME robotic system in subjects with poststroke hemiparesis. IEEE Trans Neural Syst Rehabil Eng. 2004;12(2):186-94. [PMID: 15218933]

DOI:10.1109/TNSRE.2004.827225

47. Malfait N, Gribble PL, Ostry DJ. Generalization of motor learning based on multiple field exposures and local adaptation. J Neurophysiol. 2005;93(6):3327-38.

[PMID: 15659531]

DOI:10.1152/jn.00883.2004 
48. Buchanan JJ, Zihlman K, Ryu YU, Wright DL. Learning and transfer of a relative phase pattern and a joint amplitude ratio in a rhythmic multijoint arm movement. J Mot Behav. 2007;39(1):49-67. [PMID: 17251171]

DOI:10.3200/JMBR.39.1.49-67

49. Haggard P, Hutchinson K, Stein J. Patterns of coordinated multi-joint movement. Exp Brain Res. 1995;107(2):254-66. [PMID: 8773244] DOI:10.1007/BF00230046

50. Nef T, Mihelj M, Riener R. ARMin: A robot for patientcooperative arm therapy. Med Biol Eng Comput. 2007; 45(9):887-900. [PMID: 17674069]

DOI:10.1007/s11517-007-0226-6

51. Dolce G, Lucca LF, Pignolo L. Robot-assisted rehabilitation of the paretic upper limb: Rationale of the ARAMIS project. J Rehabil Med. 2009;41(12):1007-1101.

[PMID: 19841833]

DOI:10.2340/16501977-0406

52. Housman SJ, Scott KM, Reinkensmeyer DJ. A randomized controlled trial of gravity-supported, computer-enhanced arm exercise for individuals with severe hemiparesis. Neurorehabil Neural Repair. 2009;23(5):505-14.

[PMID: 19237734]

DOI:10.1177/1545968308331148

53. Sugar TG, He J, Koeneman EJ, Koeneman JB, Herman R, Huang H, Schultz RS, Herring DE, Wanberg J, Balasubramanian S, Swenson P, Ward JA. Design and control of RUPERT: A device for robotic upper extremity repetitive therapy. IEEE Trans Neural Syst Rehabil Eng. 2007;15(3): 336-46. [PMID: 17894266] DOI:10.1109/TNSRE.2007.903903

54. Carignan C, Tang J, Roderick S, Naylor M. A configuration-space approach to controlling a rehabilitation arm exoskeleton. Proceedings of the IEEE 10th International Conference on Rehabilitation Robotics; 2007 Jun 13-15; Noordwijk, Netherlands. Los Alamitos (CA): IEEE; 2007. p. 179-87.

55. Rosen J, Perry JC. Upper limb powered exoskeleton. Int J HR. 2007;4(3):529-48. DOI:10.1142/S021984360700114X

56. Stienen AH, Hekman EE, Van der Helm FC, Van der Kooij $\mathrm{H}$. Self-aligning exoskeleton axes through decoupling of joint rotations and translations. IEEE Trans Robot. 2009; 25(3):628-33.

57. Duschau-Wicke A, Von Zitzewitz J, Caprez A, Lunenburger L, Riener R. Path control: A method for patientcooperative robot-aided gait rehabilitation. IEEE Trans Neural Syst Rehabil Eng. 2010;18(1):38-48.

[PMID: 20194054]

DOI:10.1109/TNSRE.2009.2033061

58. Huang VS, Krakauer JW. Robotic neurorehabilitation: A computational motor learning perspective. J Neuroeng Rehabil. 2009;6:5. [PMID: 19243614] DOI:10.1186/1743-0003-6-5
59. Stefan K, Kunesch E, Cohen LG, Benecke R, Classen J. Induction of plasticity in the human motor cortex by paired associative stimulation. Brain. 2000;123(3):572-84. [PMID: 10686179] DOI:10.1093/brain/123.3.572

60. Wolters A, Sandbrink F, Schlottmann A, Kunesch E, Stefan K, Cohen LG, Benecke R, Classen J. A temporally asymmetric Hebbian rule governing plasticity in the human motor cortex. J Neurophysiol. 2003;89(5):2339-45.

[PMID: 12612033] DOI:10.1152/jn.00900.2002

61. Taub E, Uswatte G, Elbert T. New treatments in neurorehabilitation founded on basic research. Nat Rev Neurosci. 2002; 3(3):228-36. [PMID: 11994754] DOI:10.1038/nrn754

62. Bastian AJ. Understanding sensorimotor adaptation and learning for rehabilitation. Curr Opin Neurol. 2008;21(6): 628-33. [PMID: 18989103] DOI:10.1097/WCO.0b013e328315a293

63. Reinkensmeyer DJ, Patton JL. Can robots help the learning of skilled actions? Exerc Sport Sci Rev. 2009;37(1):43-51. [PMID: 19098524] DOI:10.1097/JES.0b013e3181912108

64. Reisman DS, Bastian AJ, Morton SM. Neurophysiologic and rehabilitation insights from the split-belt and other locomotor adaptation paradigms. Phys Ther. 2010;90(2): 187-95. [PMID: 20023001] DOI:10.2522/ptj.20090073

65. Winstein CJ. Knowledge of results and motor learningImplications for physical therapy. Phys Ther. 1991;71(2): 140-49. [PMID: 1989009]

66. Zwicker JG, Harris SR. A reflection on motor learning theory in pediatric occupational therapy practice. Can J Occup Ther. 2009;76(1):29-37. [PMID: 19341020]

67. Garvey MA, Giannetti ML, Alter KE, Lum PS. Cerebral palsy: New approaches to therapy. Curr Neurol Neurosci Rep. 2007;7(2):147-55. [PMID: 17324366] DOI:10.1007/s11910-007-0010-X

68. Marchal-Crespo L, McHughen S, Cramer SC, Reinkensmeyer DJ. The effect of haptic guidance, aging, and initial skill level on motor learning of a steering task. Exp Brain Res. 2010;201(2):209-20. [PMID: 19820920] DOI:10.1007/s00221-009-2026-8

69. Milot MH, Marchal-Crespo L, Green CS, Cramer SC, Reinkensmeyer DJ. Comparison of error-amplification and haptic-guidance training techniques for learning of a timing-based motor task by healthy individuals. Exp Brain Res. 2010;201(2):119-31. [PMID: 19787345] DOI:10.1007/s00221-009-2014-z

70. Liu J, Cramer SC, Reinkensmeyer DJ. Learning to perform a new movement with robotic assistance: Comparison of haptic guidance and visual demonstration. J Neuroeng 
Rehabil. 2006;3:20. [PMID: 16945148]

DOI:10.1186/1743-0003-3-20

71. Stefan K, Cohen LG, Duque J, Mazzocchio R, Celnik P, Sawaki L, Ungerleider L, Classen J. Formation of a motor memory by action observation. J Neurosci. 2005;25(41): 9339-46. [PMID: 16221842]

DOI:10.1523/JNEUROSCI.2282-05.2005

72. Mulder T. Motor imagery and action observation: Cognitive tools for rehabilitation. J Neural Transm. 2007;114(10): 1265-78. [PMID: 17579805] DOI:10.1007/s00702-007-0763-z

73. Staubli P, Nef T, Klamroth-Marganska V, Riener R. Effects of intensive arm training with the rehabilitation robot ARMin II in chronic stroke patients: Four single-cases. J Neuroeng Rehabil. 2009;6:46. [PMID: 20017939] DOI:10.1186/1743-0003-6-46

74. Nef T, Lum P. Improving backdrivability in geared rehabilitation robots. Med Biol Eng Comput. 2009;47(4):441-47. [PMID: 19184156] DOI:10.1007/s11517-009-0437-0

75. Nef T, Guidali M, Riener R. ARMin III-Arm therapy exoskeleton with an ergonomic shoulder actuation. Appl Bionics Biomech. 2009;6:127-42. DOI:10.1080/11762320902840179

76. Liu KP, Chan CC, Lee TM, Hui-Chan CW. Mental imagery for promoting relearning for people after stroke: A randomized controlled trial. Arch Phys Med Rehabil. 2004;85(9): 1403-8. [PMID: 15375808] DOI:10.1016/j.apmr.2003.12.035

77. Van Asseldonk EH, Wessels M, Stienen AH, Van der Helm FC, Van der Kooij H. Influence of haptic guidance in learning a novel visuomotor task. J Physiol Paris. 2009;103(3-5): 276-85. [PMID: 19665551] DOI:10.1016/j.jphysparis.2009.08.010

78. Scheidt RA, Reinkensmeyer DJ, Conditt MA, Rymer WZ, Mussa-Ivaldi FA. Persistence of motor adaptation during constrained, multi-joint, arm movements. J Neurophysiol. 2000;84(2):853-62. [PMID: 10938312]

79. Lewek MD, Cruz TH, Moore JL, Roth HR, Dhaher YY, Hornby TG. Allowing intralimb kinematic variability during locomotor training poststroke improves kinematic consistency: A subgroup analysis from a randomized clinical trial. Phys Ther. 2009;89(8):829-39. [PMID: 19520734] DOI:10.2522/ptj.20080180

80. Wulf G, Schmidt RA. Variability in practice: Facilitation in retention and transfer through schema formation or context effects? J Mot Behav. 1988;20(2):133-49.

[PMID: 15075124]

81. Cai LL, Fong AJ, Otoshi CK, Liang Y, Burdick JW, Roy RR, Edgerton VR. Implications of assist-as-needed robotic step training after a complete spinal cord injury on intrinsic strategies of motor learning. J Neurosci. 2006;26(41):
10564-568. [PMID: 17035542]

DOI:10.1523/JNEUROSCI.2266-06.2006

82. Lynch D, Ferraro M, Krol J, Trudell CM, Christos P, Volpe BT. Continuous passive motion improves shoulder joint integrity following stroke. Clin Rehabil. 2005;19(6):594-99.

[PMID: 16180594]

DOI:10.1191/0269215505cr901oa

83. Hu XL, Tong KY, Song R, Zheng XJ, Leung WW. A comparison between electromyography-driven robot and passive motion device on wrist rehabilitation for chronic stroke. Neurorehabil Neural Repair. 2009;23(8):837-46.

[PMID: 19531605]

DOI:10.1177/1545968309338191

84. Bluteau J, Coquillart S, Payan Y, Gentaz E. Haptic guidance improves the visuo-manual tracking of trajectories. PLoS One. 2008;3(3):e1775. [PMID: 18335049]

85. Lewis GN, Perreault EJ. An assessment of robot-assisted bimanual movements on upper limb motor coordination following stroke. IEEE Trans Neural Syst Rehabil Eng. 2009; 17(6):595-604. [PMID: 19666342]

DOI:10.1109/TNSRE.2009.2029315

86. Vallery H, Van Asseldonk EH, Buss M, Van der Kooij H. Reference trajectory generation for rehabilitation robots: Complementary limb motion estimation. IEEE Trans Neural Syst Rehabil Eng. 2009;17(1):23-30. [PMID: 19211320] DOI:10.1109/TNSRE.2008.2008278

87. Stein J, Narendran K, McBean J, Krebs K, Hughes R. Electromyography-controlled exoskeletal upper-limb-powered orthosis for exercise training after stroke. Am J Phys Med Rehabil. 2007;86(4):255-61. [PMID: 17413538] DOI:10.1097/PHM.0b013e3180383cc5

88. Dipietro L, Ferraro M, Palazzolo JJ, Krebs HI, Volpe BT, Hogan N. Customized interactive robotic treatment for stroke: EMG-triggered therapy. IEEE Trans Neural Syst Rehabil Eng. 2005;13(3):325-34. [PMID: 16200756] DOI:10.1109/TNSRE.2005.850423

89. Wolbrecht ET, Chan V, Reinkensmeyer DJ, Bobrow JE. Optimizing compliant, model-based robotic assistance to promote neurorehabilitation. IEEE Trans Neural Syst Rehabil Eng. 2008;16(3):286-97. [PMID: 18586608] DOI:10.1109/TNSRE.2008.918389

90. Housman SJ, Scott KM, Reinkensmeyer DJ. A randomized controlled trial of gravity-supported, computer-enhanced arm exercise for individuals with severe hemiparesis. Neurorehabil Neural Repair. 2009;23(5):505-14.

[PMID: 19237734]

DOI:10.1177/1545968308331148

91. Ellis MD, Sukal-Moulton T, Dewald JP. Progressive shoulder abduction loading is a crucial element of arm rehabilitation in chronic stroke. Neurorehabil Neural Repair. 2009; 23(8):862-69. [PMID: 19454622] DOI:10.1177/1545968309332927 
92. Prange GB, Jannink MJ, Stienen AH, Van der Kooij H, Ijzerman MJ, Hermens HJ. Influence of gravity compensation on muscle activation patterns during different temporal phases of arm movements of stroke patients. Neurorehabil Neural Repair. 2009;23(5):478-85. [PMID: 19190089] DOI:10.1177/1545968308328720

93. Iwamuro BT, Cruz EG, Connelly LL, Fischer HC, Kamper DG. Effect of a gravity-compensating orthosis on reaching after stroke: Evaluation of the Therapy Assistant WREX. Arch Phys Med Rehabil. 2008;89(11):2121-28. [PMID: 18996241]

DOI:10.1016/j.apmr.2008.04.022

94. Brokaw EB. Hand spring operated movement enhancer (HandSOME) device design for hand rehabilitation after stroke [MBE thesis]. Washington (DC): Catholic University of America; 2009.

95. Brokaw EB, Holley RJ, Lum PS. Hand Spring Operated Movement Enhancer (HandSOME) device for hand rehabilitation after stroke. Proceedings of the 2010 Annual International Conference of the IEEE Engineering in Medicine and Biology Society; 2010 Aug 31-Sep 4; Buenos Aires, Argentina. Los Alamitos (CA): IEEE; 2010.
96. Krebs HI, Mernoff S, Fasoli SE, Hughes R, Stein J, Hogan N. A comparison of functional and impairment-based robotic training in severe to moderate chronic stroke: A pilot study. NeuroRehabilitation. 2008;23(1):81-87. [PMID: 18356591]

Submitted for publication April 11, 2010. Accepted in revised form December 14, 2010.

This article and any supplementary material should be cited as follows:

Brokaw EB, Murray T, Nef T, Lum PS. Retraining of interjoint arm coordination after stroke using robotassisted time-independent functional training. J Rehabil Res Dev. 2011;48(4):299-316. DOI:10.1682/JRRD.2010.04.0064

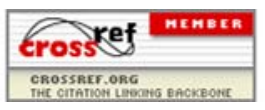

